\title{
IR-BASED INTELLIGENT HIGHWAY LIGHTING SYSTEM
}

\author{
Thanga Dhiwan $V^{1}$, E. Seethalakshmi ${ }^{2}$, Mr.R. Rajaraman ${ }^{3}$ \\ ${ }^{1}$ Student, Department of ECE, R.M.K. Engineering College, Kavaraipettai, Chennai, Tamilnadu. \\ ${ }^{2}$ Assistant Professor, Department of ECE, R.M.K. Engineering College, Kavaraipettai, Chennai, Tamilnadu \\ ${ }^{3}$ Assistant Professor, Department of S\&H, R.M.K. Engineering College, Kavaraipettai,
}

Chennai, Tamilnadu

\begin{abstract}
This paper is proposed based on an automatic highway light controller. This device has overcome the drawback of an existing system. By this system, the Arduino board had its link with the IR sensor, LED, LDR, input $5 \mathrm{v}$. Intelligent highway light sensing is mentioned to the system of sensing the movement of vehicles that take place to switch on/off the highway light when vehicles approach the light lamp, Our idea is the light became dim when no activity is detected in highway road. if any activity is detected in the road the dim light will become bright till the vehicle detection is stopped. We also added an LDR in this project to off the light during daytime and ON during nighttime. we make the light dim during night time to avoid any accident to people, robberies, etc. We use Arduino board to consume less energy and cost-efficient.
\end{abstract}

Keywords - LDR, LED, ARDUINO, Energy, Highway Light

\section{INTRODUCTION}

The highway lights are the most important of things in highway todays for safety purposes and avoiding accidents during night time travel. Providing road lighting is one of the essential and notable ones. Lighting can account for 15$40 \%$ of the total energy bill in typical cities highway worldwide. [1] In our project is mainly concern with economic and social stability. In today's busy time no one can bother about switch OFF/ON the electrical appliances when not in use. Inefficient lighting wastes notable economical resources each year, and weak lighting creates risky conditions. The main occupation of the present field technologies is Automation, Power reducer, and cost-efficient. Automation is a method to reduce manpower with the help of intelligent systems. Automation plays a most important role in the day to day life and also save energy in a various way. Automatic systems are being used in all kinds of manual systems. Power saving is the main objective to the sources of the power are getting diminished due to various kind of reason. Designing a system with cost-efficient is more important and required. To resolve all these problems, an automatic highway light control system is implemented. The main objective of our project is to give the best solution to reduce the electrical wastage in operating highway lights, in this period of automation humans are without rest and are not to work the system by the manual operations. Rapid improvement in embedded systems has given way path for the designing and development of microcontroller-based automatic control systems. [2] Our project presents an automatic highway light controller using an Arduino board, IR sensor, LDR. This technology is to reduce human work by physically on/off the highway light. And also reduce the work of humans on a rainy day to on /off the highway light. The research work gives a clear idea of automatic control of road lights as a result of this project we can save energy and use for future purpose. In the field of industrialization, automation plays a major role, it also reduces the human working with a machine to help the worker with physical Work. [3] Automation largely reduces human needs and human work. Highway light is an important factor that plays in nowadays, the highway lights are not complicated one but with the development of urbanization, the number of highways increases fastly to overcome the traffic. [4] By this method also reduce waste usage of power and electricity. The light is on/off when sunset and sunrise. The increase and decrease the brightness of the light by vehicles approaches. The system of sensing the movement of vehicles that take place to switch on/off the highway light when vehicles approach a light lamp, the light became dim when no activity is noted in highway, if any ray is detected in the roadway the dim light becomes bright and the light glows bright till the vehicle detection is stops. The work of LDR in this project to off the light during daytime and on during nighttime.

\section{II.LITERATURE STUDY:}

Author Parkash proposed his idea in "Internet of Things Based Intelligent Street Lighting System for Smart City" (topic) The highway road light is control by IOT, road light can Be control from anywhere and anytime through the 


\section{International Advanced Research Journal in Science, Engineering and Technology}

Vol. 8, Issue 6, June 2021

\section{DOI: 10.17148/IARJSET.2021.8690}

internet. This project is executed with a smart embedded system that powers the road lights based on the detection of vehicles or any other obstacles on the road. whenever the obstacle is detected on the road within the identified time the light will get automatically ON, according to the obstacle detection stop it will OFF and the same information can be accessed through the internet. The drop backs are resolved by this project.

Author A. Santhosh Reddy proposed his idea in "A Smart Highway Lighting System Using IOT" (topic). With the assist of a Proximity sensor, LDR, Current sensor, Relay, and raspberry pi. With the help of these components, these sensors monitored the motion of any vehicle passing through them and that can be noted and by using LDR lights can be turned on. If no motion means it turns OFF. But there was some dropback to ON/OFF the lights of the highway that are resolved by this project.

Author Monali Y. Khachane proposed his idea in “ Intelligent Street Lighting System”( topic ). The highway light on when the vehicles come near to light lamp and afterward the light turns off by using a microcontroller, IR sensor. If no one on the road the light would be in off condition. It is a risk for people.

The existing system fallback is unknown and set on in this system. This project ON/OFF the lights in the daytime as well as in night time, and make dim and bright when vehicle approach.

\section{III.EXISTING SYSTEM:}

In the existing system, the highway lights are operated by hand to turn ON and OFF. So we need manpower to operate these, we have put forward a very good system in which we don't need manpower and manually operating the highways road lights when vehicles approach we have set down an LDR and Arduino board which automatically turns $\mathrm{ON}$ and OFF the lights depending on the sunlight and vehicles come.

\section{IV.PROPOSED METHOD:}

The road lights will be controlled the night. If the sun sets the light will be on and light off if the sun is rising. We used Arduino board, 5 IR sensors 5 LED's 1 LDR sensor which plays a key role in the turning ON and OFF of the lamps and dims the light. The Arduino UNO Microcontroller acts as an interface while converting the Analog input into a digital form of output and makes the lamp glow bright and dull. The code is dumped into the Arduino board by using an Arduino IDE software. when the obstacle comes near to the lamplight the dim light show high brightness by following 2 lamp light and the obstacle move far away the light will dim. If nobody or no obstacle is there means the lamp light is in dim mode. If any obstacle came near to IR sensor means continuously the light will show high intensity.

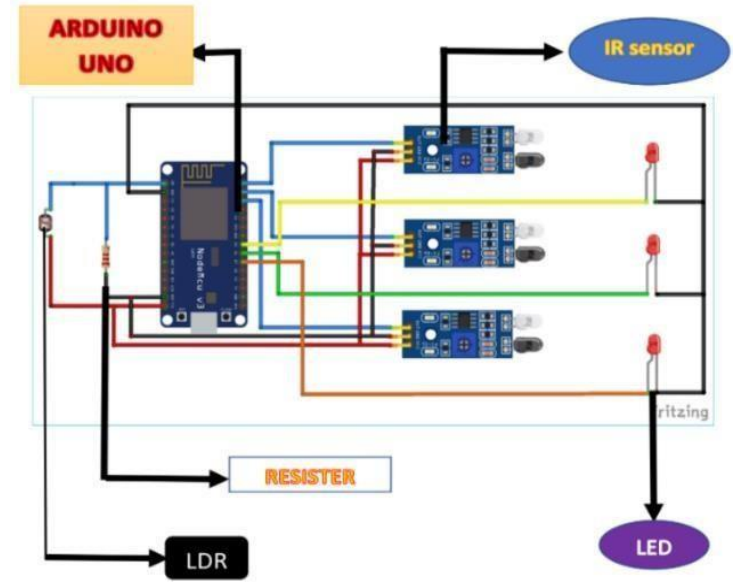

Figure 4.1 block diagram

\section{CONNECTION IN ARDUINO BOARD:}

Output of the LDR pin has its connection with the A0 (analog) port in Arduino UNO.

Connection of all output of the IR sensors to port numbers A1, A2, A3, A4, and A5, the input signal to the board. Connect all ground IR sensors to the GND port.

The output signals from LED are connected to ports 5, 6, 9, 10, and 11.

All the negative terminals of LEDs are been connected to the GND port.

Voltage to the Arduino (5V). 


\section{DOI: $10.17148 / I A R J S E T .2021 .8690$}

Figure 4.2 is the circuit connection diagram of the highway road light. There is enough sunlight in the environment, LDR gives more resistance and acts as non-conductor, while in dark mode the LDR show low resistance path and allows the flows of current, the light switch on under low light environment and these are maintained by an Arduino UNO board and work done under 5v DC power supply. If any things come near to IR sensors, as IR LED emits the radiation and receives the signal back to IR photodiode by the object. Hence, an obstacle is noted. The intensity of

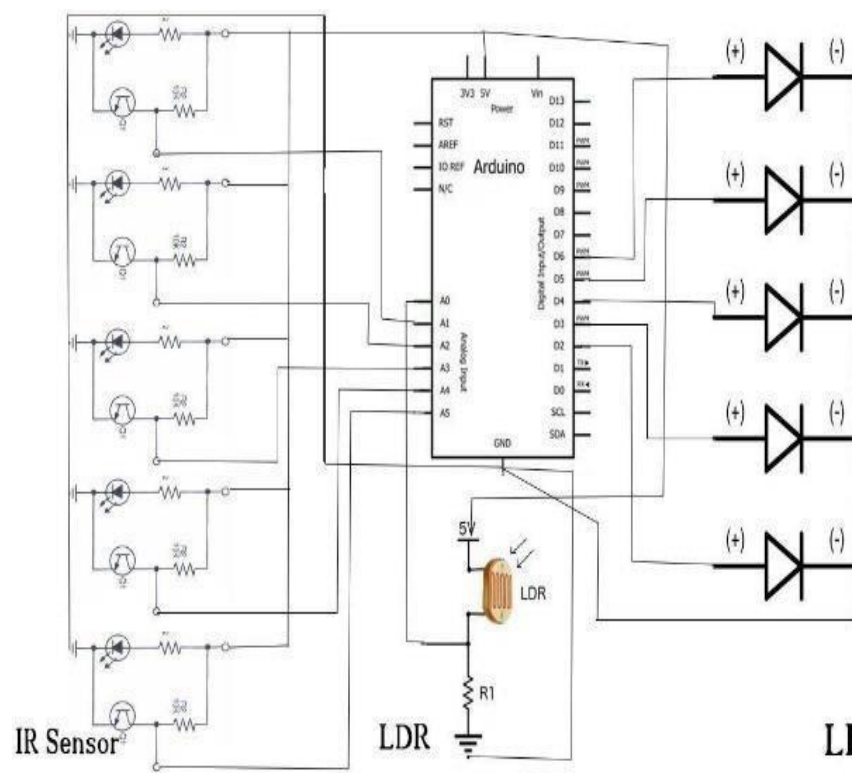

Figure 4.2 circuit connection

LED's remains at a low level (when no object is detected) with the help of the pulse Width Modulation (PWM) method whereas the analog signal is turned into a digital signal, intensity is increase - decrease activity of LEDs taken place in that manner, the LEDs seem to glow dimly when seen by the naked eye. Hence, the intensity of the lights is monitored. The coding was applied to an Arduino UNO board by using Arduino software.

\section{V.HARDWARE REQUIREMENT:}

We make the connections as per the circuit diagram. The code is very important in the working process. Nowadays, the highways Light System is most important for a smart city Infrastructure. The main function is to give lighting to the highway using a Sensor, an Arduino board is to save the power energy. The existing system they using normal bulbs light, so it takes more current and expensive so we must use LED.

The system is divided into five major parts listed below:

-MICROCONTROLLER

-INFRARED SENSORS

-LIGHT-DEPENDENT RESISTANCE

-LIGHT-EMITTING DIODE

-RESISTOR

The above mention parts are briefly explained as below:

\section{A.MICROCONTROLLER :}

From figure 5.1 Arduino UNO microcontroller is used in this project, it is based on ATmega328. It is an open-source electronic platform so, it is easy to use both the software part as well as the hardware part. It is the cheapest and costefficient board. It consists of 14 input/output \& 6 analog pins. It is easy to read input code The software used is ARDUINO IDE.[5]

\section{Figure 5.1 MICROCONTROLLER}

\section{B.INFRARED SENSORS :}

From figure 5.2 An infrared sensor is an active device that emits and detects infrared radiation. An IR sensor can detect the motion as well as the activity of any object when it came near to sensor, This sensors will monitor only the infrared radiation, an IR sensor is a device that detects IR radiation falling on it.[6] 


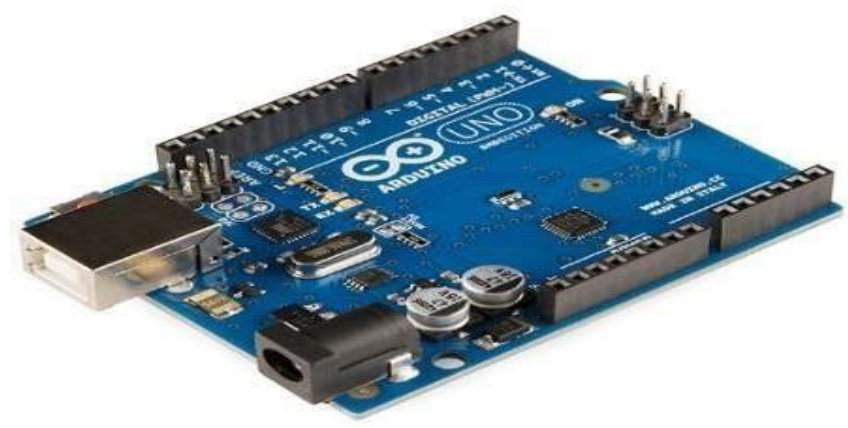

Figure 5.2 IR SENSOR C.LIGHT DEPENDENT RESISTANCE :

From figure 5.3 LDR is a device that has a resistance to change with light intensity when a light ray falls on it. It is a nonlinear device. Resistance of an LDR is very high, sometimes it may be $1000000 \mathrm{ohms}$, but when they have high brightness with light resistance reduce completely. It changes its electrical characteristics when the presence of visible or invisible light. The best devices of this type are the light-dependent resistor (LDR), the photodiode, and the phototransistors.[7]

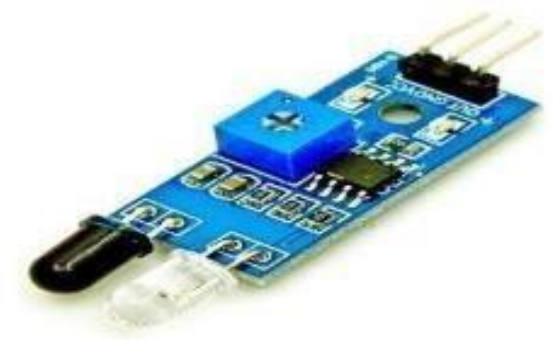

\section{PROPERTY :}

1.High reliability.

2.Light Weight.

3.Wide Spectral Response.

4.Wide ambient Temperature range[8]

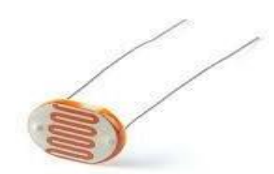

Figure 5.3 LIGHT DEPENDENT RESISTANCE

\section{D.LIGHT EMITTING DIODE :}

From figure 5.4 A light-emitting diode (LED) is a two-lead semiconductor device. LED is a $\mathrm{p}-\mathrm{n}$ junction diode that emits light when we current move on it or turn it on. The big terminal is an anode and the small terminal is a cathode. When a current is a pass to the terminal, electrons have to recombine with electron holes within the diode, releasing energy in the form of photons. This process is known as electroluminescence, and the color of the light is determined by the energy bandgap of the semiconductor. LEDs are typically small.[9]

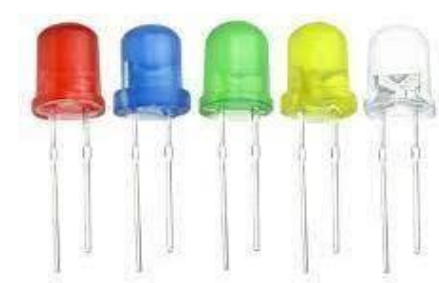

Figure 5.4 LIGHT EMITTING DIODE 


\section{International Advanced Research Journal in Science, Engineering and Technology}

Vol. 8, Issue 6, June 2021

\section{DOI: $10.17148 / I A R J S E T .2021 .8690$}

\section{E.RESISTOR :}

From figure 5.5 The Resistor is a passive device. It opposes the current flow or electron flow in the circuit. The Resistor sent a fixed current through the circuit. It protects the device from any damage. We use a $370 \mathrm{ohms}$ resistor for LED and a $1 \mathrm{k}$ ohms resistor for LDR.[10]

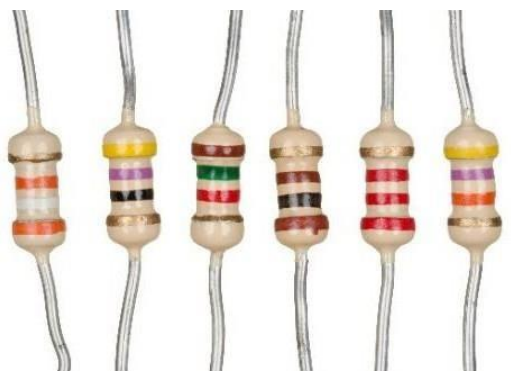

Figure 5.5 RESISTER

\section{VI.SOFTWARE:}

The code is done with help of Arduino IDE software (figure 6.1). It is free source software.It is easy to code in that software platform. We use the c++ language to code.[11]

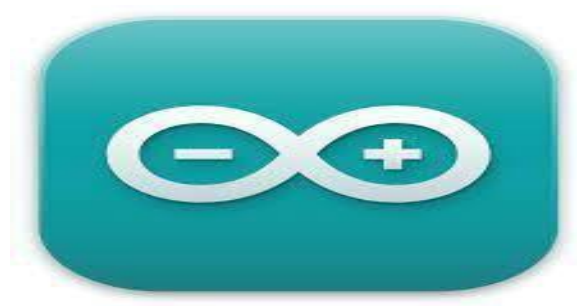

Figure 6.1. Arduino IDE

\section{VII.RESULT:}

The highway light device application can be mainly helpful in normal roads, highways, expressways, etc. This project can also be fix or estimate in parking areas of malls, hotels, industrial lighting, etc. The cost of the maintenance can be reduced as the life span and longevity of LEDs is higher than Neon based lights which are normally used as highway road. As the lights are automatically fixed ON or OFF, a huge amount of energy can be saved. This system low cost for buying, less installation time and money, and maintenance costs are very low and more efficient as compared to the others system. To reduce energy consumption, manpower. Arduino UNO is the cheapest and easy to code. This project will help full for people to avoid the fear to go on the road, And the light automatically on/off when sunset. Hence, this project works automatically without manpower. It on/off light correctly when the sunset and rises. It is in the dim mode at night time for people safety purposes, but other existing projects do not use that light dim mode stage. I fix dynamo in speed break to produce energy for light to reduce the energy consumption and produce the energy from dynamo itself. And also use solar panels to produce energy. There is no switch to on off. Other use only one light to glow when any approaches I use to glow two light. 


\section{International Advanced Research Journal in Science, Engineering and Technology}

Vol. 8, Issue 6, June 2021

\section{DOI: $10.17148 / I A R J S E T .2021 .8690$}

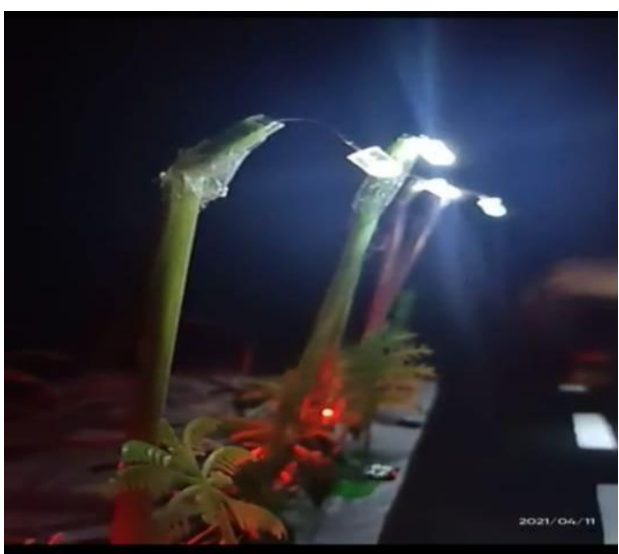

Figure 8.1. Result

\section{VIII.REFERENCES:}

1.Parkash, Prabu V, Dandu Rajendra, P.G Diploma Student, Dept. of Embedded System and Design, NIELIT, Calicut, Kerala, India. Issue 5, May 2016, International Journal of Innovative Research in Science, Engineering, and Technology.

2.a.santhosh reddy, p.sarath naga sai ram, Sudhadukkipati international journal of scientific \& technology research volume 8 , issue 12 , December 2019.

3.Monali Y. Khachane, Yashwantrao Chavan School of Rural Development, Shivaji University, Kolhapur. International Journal of Engineering Research in Computer Science and Engineering (IJERCSE) Vol 5, Issue 02, February 2018

4.IsahAbdulazeez Watson, OshomahAbdulaiBraimah,Alexander Omoregie "Design and Implementation of an Automatic Street Light Control System" International Journal of Emerging Technology and Advanced Engineering, Volume 5, Issue 3, March 2015

5.S. Suganya, R. Sinduja, T. Sowmiya\& S. Senthilkumar, Street light glow on detecting vehicle movement using sensor Soledad Escolar, JesúsCarretero, Maria- Cristina Marinescu and Stefano Chessa "Estimating Energy Savings in Smart Street Lighting by Using an Adaptive Control System” International Journal of Distributed Sensor Networks Volume 2014, Article ID 971587

6.International Journal of Innovative Research in Computer and Communication Engineering (An ISO 3297: 2007 Certified Organization) Website: www.ijircce.com Vol. 5, Issue 3, March 2017 Smart Street Light Using Arduino Uno Microcontroller.

7.D. A. Devi and A. Kumar, Design and Implementation of CPLD based Solar Power Saving System for Street Lightsand Automatic Traffic Controller, International Journalof Scientific and Research Publications, Vol. 2, Issue11, November 2012.

8.Prakash T; Arun G; Arun Kumar B; Deepan S; Kalyana Venkata Ramanan. "IoT Based Smart Irrigation for Multi Cropping System". International Research Journal on Advanced Science Hub, 2, 4, 2020, 7-12. doi: 10.47392/irjash.2020.20

9.K. S. Sudhakar, A. A. Anil, K. C. Ashok and S. S. Bhaskar, Automatic Street Light Control System, International Journal of Emerging Technology and Advanced Engineering, Vol. 3, May 2013, PP. 188- 189.

10.V. Shiva Prasad Nayak, A Vinay Krishna, Asmita Rangari, B.Sammunayak, and K. Madhukar, Development of street lighting system with vehicular sensing at low light intensity based on zigbee intelligence,\| IEEE Fifth International Conference On Recent Trends In Information Technology, 2016.

11.Seher Yusnieva Kadirova, Daniel Ivanov Kajtsanov, A Real time street lighting control system, in "Microclimatic data collection multisensory system for design of energy model in residential buildings", Electrical Apparatus and Technologies (SIELA) 2018 20th International Symposium on, pp. 1-3, 2018.

12.Dhiraj Sunehra, Sangem Rajasri (2017) "Automatic street light control system using wireless sensor networks" have been discus sed in area of power system.

13.Naga Siva Rama Murthy V. "Micro controller based Power Factor Correction". International Research Journal on Advanced Science Hub, 2, Special Issue ICIES 9S, 2020, 108-115. doi: 10.47392/irjash.2020.170

14.Mustafa Saad, (October 2013) “Automatic Street Light Control System Using Microcontroller".Swati Rajesh Parekar and Manoj M. Dongre, -An intelligent system for monitoring and controlling of street light using GSM technology, IEEE 2015 International Conference on Information Processing (ICIP) Dec 16-19, 2015.

15.Jijusasikumar S; Kaviya K; Logida R; Chinmaya S; Sangeetha K. "Gas Leakage Monitoring System Using IOT". International Research Journal on Advanced Science Hub, 3, Special Issue ICARD-2021 3S, 2021, 108-111. doi: 10.47392/irjash.2021.075

16.Deshmukh K P. "Wireless Transceiver Module HC-12 based Automatic Water-level Monitoring and Control System". International Research Journal on Advanced Science Hub, 2, 10, 2020, 24-28. doi: 10.47392/irjash.2020.184 